\title{
Sphingomonadaceae: Protective against breast cancer?
}

\author{
Ebidor Ufoumanefe Lawani-Luwaji ${ }^{*}$ and Tolulope Alade
}

\begin{abstract}
Background: Breast cancer is the most common malignancy and one of the leading causes of cancer-linked deaths in women. The development of the mammary gland is regulated by oestrogen whose activities have also been linked with various diseases including breast cancer. Research has shown that host-microbiota relationship plays a role in human health and disease, so we investigated the association between breast microbiota and breast cancer. A search of the literature was conducted using search tools such as Google Scholar, PubMed, EBSCO and Cochrane library with the terms breast cancer, breast microbiota, microbiome and dysbiosis. A further search included Sphingomonas, Sphingobium yanoikuyae and oestrogen. The search terms were combined in original forms to get relevant studies related to the subject under review. All articles written in English were included and publication dates were not limited.

Conclusion: Taken together, the studies show that Sphingobium yanoikuyae might have a protective role in breast cancer, especially oestrogen positive, and highlights the need for further investigation into the use of the bacteria for prevention and possibly management of breast cancer.
\end{abstract}

Keywords: Breast cancer, Microbiota, Dysbiosis, Sphingomonas

\section{Background}

Breast carcinoma embraces a group of diseases with definite clinical, molecular and histopathologic properties. It is the most common malignancy in females and is one of the leading causes of cancer-related deaths. It has also been is described on the molecular level as a heterogeneous disease (Harbeck 2020).

The human breast is characterised by connective, fat and glandular tissues separated into lobes with a web of ducts spreading to the nipples from the lobes. The mammary glands develops in three stages, it starts during puberty and development continues during lactation, and finally in pregnancy. The process is regulated by the autogenous hormone oestrogen which is produced by the ovaries; therefore, the mammary glands create a system

*Correspondence: Eb2kng@yahoo.com

College of Health Sciences, Niger Delta University, Wilberforce Island, Amassoma, Bayelsa State, Nigeria to understand oestrogen receptor signalling (Korach et al. 2019).

There are two main types of breast cancer: in situ and invasive carcinoma. In situ breast carcinoma emanates from either the lobular or ductal epithelium and is restricted to these spaces without invading the mammary basement membrane, which makes up the boundaries. When the malignancy extends from the lobes or ducts past the basement membrane, such malignancy is referred to as invasive carcinoma. The principal cause of death from breast cancer is mainly because of the metastasis of invasive disease (Richie and Swanson 2003).

Breast cancer is further divided into molecular subtypes: luminal A and luminal B, triple-negative/basal-like breast cancer, HER2-enriched breast cancer and normallike breast cancer. Breast tumours that express either ER and or progesterone receptor (PR) and HER2 are considered as hormone receptor-positive, while tumours that do not express any of the receptors are known as triplenegative breast cancers (TNBC) (Harbeck 2020). 
Oestrogen has several physiological roles in the body and not limited to maintaining the female reproductive organs. The hormone also initiates and exacerbate several disease conditions including gastrointestinal cancers such as gastric cancer, colon cancer, oesophageal cancer (Chen et al. 2019) and breast cancer (Platet et al. 2004). The effect of oestrogen is exerted in a classical and non-classical manner, the classical action of oestrogen is orchestrated through the protein receptors isoform (ER $\alpha$ and ER $\beta$ ), and transcription factors are involved in the non-classical pathway (Thomas and Potter 2013).

These receptors are naturally present and expressed in the mammary gland but have been reported to mediate oestrogen signalling in hormone-dependent breast cancer. ER $\alpha$ is a predictive indicator in breast cancer, but the prognostic role of ER $\beta$ in breast cancer is less clear (Burns and Korach 2012). It is documented that approximately $70 \%$ of primary breast malignancies are oestrogen receptor-positive, and even though the use of targeted hormonal and biological treatments have increased survival rates, metastasis remains a significant clinical problem (Zhang et al. 2013).

The binding of oestrogen to the receptors encourages an upsurge in DNA replication and cell division with increased replication errors. Accumulation of mutated DNA upsets the regular cell processes such as DNA repair and apoptosis and encourages the proliferation of mammary cells (Deroo and Korach 2006).

Oestrogen circulates in the bloodstream as free molecules or bound to proteins for entry into target tissues. It is eliminated from the body by conjugation through glucuronidation, sulfonation or methylation (Plottel and Blaser 2011). Conjugation is a detoxification mechanism by which hormones are made water-soluble and excreted in the urine or faeces, or turned into a more lipophilic moiety (fats, oils, lipids, and non-polar solvents) with elevated half-lives (Lakhani et al. 2003).

Conjugated oestrogen is a target for the gene products of the estrobolome, which is a collection of gene products from enteric bacteria with the capability of digesting oestrogen. This activity by the estrobolome influences the level of circulating oestrogen in the bloodstream. A reduction of circulating oestrogen by the estrobolome will have resultant physiologic effects. An estrobolome that favours oestrogen deconjugation encourages the reabsorption of free oestrogen, therefore contributing to the host oestrogen levels. Some factors have been found to affect the distribution of the estrobolome and include both environmental and host-specific elements (Plottel and Blaser 2011).

There has been an advance in microbiome researches over the years which is helping cancer scientist to reinform and increase the knowledge of human biology.
Research has shown that bacteria species possessing the enzymes $\beta$-glucuronides and $\beta$-glucuronidases are involved in oestrogen conjugation and deconjugation (Plottel and Blaser 2011). We conducted a scoping review designed at summarising and analysing published scientific articles regarding breast cancer and breast microbiota. This review is aimed at identifying microbial specie(s) that could have a protective role against breast cancer.

\section{Method \\ Study design}

The review was designed by identifying a distinct research objective and search strategy by finding relevant articles, extracting, analysing, discussing and reporting the results. We designed the review process (Fig. 1) according to the framework designed by Arksey and O'Malley (2005). We searched online literature articles in the databases of EBSCO (Medline), Google Scholar, PubMed and Cochrane. We made use of the search terms breast cancer, breast microbiota or breast microbolome and Sphingobium yanoikuyae. Also, we included all the appropriate scientific articles involving human subjects written in English in the review.

\section{Main text}

\section{Breast microbiota}

The human microbiota is diverse with the human intestinal tract, a rich environment bustling with trillions of microbes. The colon is home to microbiota with concentrations of $10^{11}-10^{12}$ cells $/ \mathrm{ml}$, which is the highest recorded for any microorganism habitat (Ley et al. 2006).

The microbiota of the breast differs from other body sites and research shows it contains both pathogenic and non-pathogenic bacteria (Urbaniak et al. 2012). Bacteria have been isolated from the lobules ducts and fatty tissues, and scientists have proposed that the breast microbiome could be beneficial because they contribute to maintaining a healthy breast tissue (Xuan et al. 2014).

The researchers showed that bacteria have been isolated from both lactating and non-lactating breast (Urbaniak et al. 2016). Major phyla identified by $16 \mathrm{~S}$ pyrosequencing are Proteobacteria, Actinobacteria, Verrucomicrobia, Deinococcus-Thermu, Firmicutes, Bacteroidetes and Fusobacteria. The most abundant phyla in breast tissue were Proteobacteria followed by Firmicutes as shown in Fig. 2 (Xuan et al. 2014; Urbaniak et al. 2016).

The maintenance of an equilibrium between the microbiota and host is delicate and a change in this balance could have a negative effect on the individuals' health leading to several disease conditions including cancer (Plottel and Blaser 2011). 


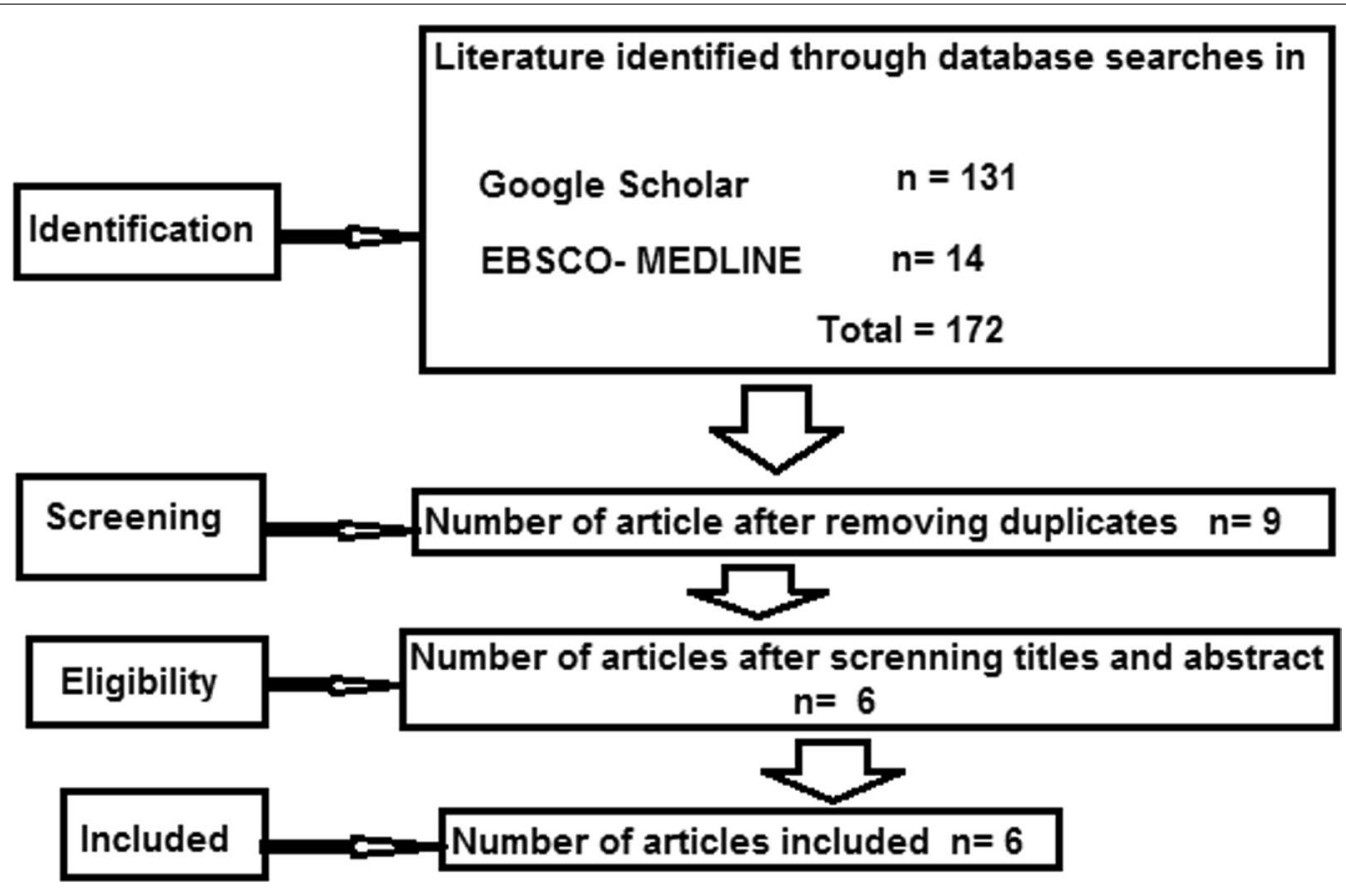

Fig. 1 Flow diagram for the review process used for the review

Dysbiosis is a phenomenon that refers to the irregular distribution or dysfunction of the microbe community in a part of an organism. It occurs when the distribution of certain microbial species changes within the community and this hamper symbiotic relationships in the microbial community (Jones 2018).

Dysbiosis upsets the microbiome equilibrium and such disruption might encourage the deconjugation and re-utilising of oestrogen with a resultant upsurge of the individual's oestrogen levels. This will contribute to an increased risk of oestrogen facilitated cancer including breast cancer (Belkaid and Hand 2014). Dysbiosis has also been involved in increases in inflammation and inflammatory cytokines which is an indication of cancer (Shapira et al. 2013).

A comparison was made between the breast microbiota of tissues from ER + ve breast cancer subjects and healthy controls using $16 \mathrm{~S}$ pyrosequencing technique. Out of the 1614 operational taxonomic units (OTS) identified, there was no significant variation in richness between the number of (OTUs) in both groups but there was a significant difference between the evenness of the microbiota community. Out of 1614, OTS detected, 11 were abundant in healthy breast tissues and three in breast tumour tissue. Bacteria belonging to the genus Sphingomonas and the specie Sphingomonas yanoikuyae was more abundant in the healthy breast tissues while in the breast tumour tissues, bacteria in the genus Methylobacterium was more abundant (Xuan et al. 2014).

Nipple aspirate fluid from breast cancer patients and healthy control subjects revealed differences between the OTUs between the two groups. Bacteria belonging to, the genus Alistipes was found only in breast cancer patients while the genus Sphingomonadaceae was more abundant in the healthy control than the breast cancer needle aspirate samples. Sequencing identified the specie to be Sphingobium yanoikuyae (Chen et al. 2019).

Free circulating DNA (cfDNA) was examined and compared in plasma samples of three breast cancer patients and healthy counterparts. The bacteria species frequently found were Acinetobacter and Mycobacterium, but in the breast cancer patients, the spp were diverse and more probable to present at high levels than the healthy counterparts. One of the breast cancer patients with multiple Sphingomonas species infections remains alive, while another patient with Pseudomonas mendocina and Pannonibacter phragmitetu passed away. The third breast cancer patient who has Acinetobacter johnsonii XBB1 like the healthy controls was seen to live a normal life (Huang et al. 2018).

\section{Sphingomonas}

Members of the Sphingomonadaceae family are known for their capacity to degrade aromatic hydrocarbons and polycyclic aromatic hydrocarbons (PAH). They are 


\section{Normal breast tissue}

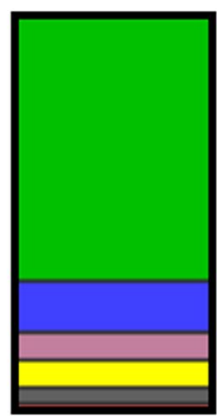

Total $=100$

\section{Breast tumour tissue}
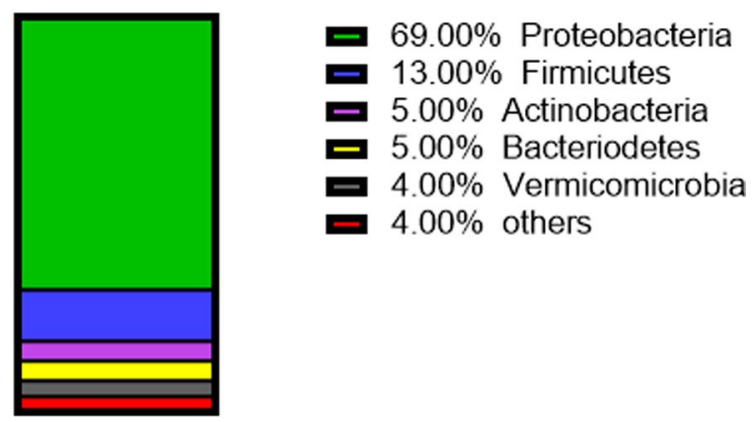

Total $=\mathbf{1 0 0}$

Fig. 2 Bacteria distribution in normal breast tissues and tumour tissues. The relative percentage of bacteria distribution at phylum level as described by Xuan et al. (2014)

highly significant environmental pollutants because of their carcinogenic properties in the body (Inoue et al. 2008). PAHs are present and prevalent in the atmosphere mainly because of inadequate combustion of fossil fuels. Individuals are exposed to these hydrocarbons from various sources, especially environmental such as air pollution (Crouse et al. 2010). PAHs can be ingested orally through the consumption of grilled or smoked foods such as meat and fish, cigarette and tobacco smoking. Also, through the consumption of inadequately washed vegetables contaminated with soil (Maanen et al. 1994; Heisterkamp and van Veen 1997; Boström et al. 2002; Gaudet et al. 2013). Paths can get into the body through the skin using dermal products containing black rubber (Inoue et al. 2008).

PAHs have been established as human carcinogens in the lungs and previous research has shown that mammary tumours can be induced by PAH, but knowledge in this field is limited regarding its association with females (White et al. 2016).
Sphingomonadaceae can be found at several natural environment habitats including both aqueous and terrestrial habitats such as marine, desert sand, water and dumpsite. Its extensive distribution in the environment arises from its scope to use varied organic compounds, growth and survive under low-nutrient conditions. Characterised by their yellow/orange pigment, they are gramnegative aerobic, non-sporing bacilli (Feng et al. 2014).

They are chemoheterotrophic and contain glycosphingolipids in their cell envelopes instead of lipopolysaccharide. The genus is subdivided into four genera: Sphingomonas, Sphingopyxis, Sphingobium and Novosphingobium (Balkwill et al. 2003).

Members of the genus sphingomonad can degrade a wide variety of PAHs and related compounds. These sphingomonads such as Novosphingobium aromaticivorans strain F199, Sphingobium sp. strain P2 and Sphingobium yanoikuyae strain B1 were found to possess an exceptional set of genes for aromatic hydrocarbon degradation. Sphingomonads can degrade both low molecular and high molecular weight PAHS and the capability to degrade these compounds is thought to be related to their physiological characteristic. The unique glycosphingolipid cell wall is thought to play a role in the degradation of PAHs (Pinyakong et al. 2003).

\section{Conclusion}

The diversity of PAHs that S. yanoikuyae can metabolise, along with the ability to digest monocyclic compounds and degrade oestrogen, puts this specie in a spotlight. It will also be a suitable candidate for a detailed analysis of the genes and enzymes involved in the metabolism of these compounds which might be beneficial for oestrogen- related cancers, especially breast cancer.

The results from the studies documented above suggest that Sphingobium yanoikuyae may have a protective role in breast cancer, especially oestrogen-positive breast cancer because of its extra ability to metabolise oestrogen. It is fascinating that a microbe, with the capability of degrading aromatic hydrocarbons and oestrogen, would be relatively increased in the healthy control and decreased in the breast cancer patients as revealed in previous studies.

Further investigation into this novel area of Sphingobium yanoikuyae and its 'protective' role in breast cancer will be a timely intervention.

\section{Abbreviations}

cfDNA: Free circulating DNA; DNA: Deoxyribonucleic acid; ER: Oestrogen receptor; ERß: Oestrogen receptors beta; HER2: Human epidermal growth factor receptor 2; OTS: Operational taxonomic units; PR: Progesterone receptor; TNBC: Triple-negative breast cancers; PAH: Polycyclic aromatic hydrocarbons. 


\section{Acknowledgements \\ Not applicable.}

\section{Authors' contributions}

EL researched data for the review and wrote the manuscript. TL also contributed to writing the manuscript and proofreading. All authors read and approved the final manuscript.

\section{Funding}

No funding has been provided for this review paper.

\section{Availability of data and materials}

Not applicable.

\section{Ethics approval and consent to participate}

Not applicable.

\section{Consent for publication}

Not applicable.

\section{Competing interests}

There is no competing interest.

Received: 23 August 2020 Accepted: 5 November 2020

Published online: 16 November 2020

\section{References}

Arksey H, O'Malley L (2005) Scoping studies: towards a methodological framework. Int J Soc Res Methodol 8(1):19-32. https://doi.org/10.1080/13645 57032000119616

Balkwill DL, Fredrickson JK, Romine MF (2003) Sphingomonas and related genera. Pacific Northwest National Lab (PNNL), Richland

Belkaid Y, Hand TW (2014) Role of the microbiota in immunity and inflammation. Cell 157(1):121-141. https://doi.org/10.1016/j.cell.2014.03.011

Boström C, Gerde P, Hanberg A, Jernström B, Johansson C, Kyrklund T, Rannug A, Törnqvist M, Victorin K, Westerholm R (2002) Cancer risk assessment, indicators, and guidelines for polycyclic aromatic hydrocarbons in the ambient air. Environ Health Perspect 110(suppl 3):451-488. https://doi. org/10.1289/ehp.110-1241197

Burns KA, Korach KS (2012) Estrogen receptors and human disease: an update. Arch Toxicol 86(10):1491-1504. https://doi.org/10.1007/s0020 4-012-0868-5

Chen C, Gong X, Yang X, Shang X, Du Q, Liao Q, Xie R, Chen Y, Xu J (2019) The roles of estrogen and estrogen receptors in gastrointestinal disease. Oncol Lett 18(6):5673-5680. https://doi.org/10.3892/ol.2019.10983

Crouse DL, Goldberg MS, Ross NA, Chen H, Labrèche F (2010) Postmenopausal breast cancer is associated with exposure to traffic-related air pollution in Montreal, Canada: a case-control study. Environ Health Perspect 118(11):1578-1583. https://doi.org/10.1289/ehp.1002221

Deroo BJ, Korach KS (2006) Estrogen receptors and human disease. J Clin Investig 116(3):561-570. https://doi.org/10.1172/JCl27987

Feng G, Yang S, Wang Y, Zhang X, Zhao G, Deng M, Zhu H (2014) Description of a Gram-negative bacterium, Sphingomonas guangdongensis sp. nov. Int J Syst Evol Microbiol 64(5):1697-1702. https://doi.org/10.1099/ijs.0.05685 3-0

Gaudet MM, Gapstur SM, Sun J, Diver WR, Hannan LM, Thun MJ (2013) Active smoking and breast cancer risk: original cohort data and meta-analysis. J Natl Cancer Inst 105(8):515-525. https://doi.org/10.1093/jnci/djt023

Harbeck N (2020) Breast cancer is a systemic disease optimally treated by a multidisciplinary team. Nat Rev Dis Primers 6(1):1-2. https://doi. org/10.1038/s41572-020-0167-z

Heisterkamp SH, van Veen MP (1997) Exposure to xenobiotics in nutrition. Model compounds: butyl benzyl phthalate (BBP), benzo [a] pyrene and fluoranthene, no. 604502, p 002. Technical report
Huang Y, Chen Y, Fan T, Chang N, Chen Y, Midha MK, Chen T, Yang H, Wang Y, Alice LY (2018) Analysis of microbial sequences in plasma cell-free DNA for early-onset breast cancer patients and healthy females. BMC Med Genom 11(1):16. https://doi.org/10.1186/s12920-018-0329-y

Inoue D, Hara S, Kashihara M, Murai Y, Danzl E, Sei K, Tsunoi S, Fujita M, Ike M (2008) Degradation of bis (4-hydroxyphenyl) methane (bisphenol F) by Sphingobium yanoikuyae strain FM-2 isolated from river water. Appl Environ Microbiol 74(2):352-358. https://doi.org/10.1128/AEM.01708-07 Jones FA (2018) Physiology of the gastrointestinal tract, 6th edn. Amsterdam, Elsevier

Korach KS, Hewitt SC, Hamilton KJ, Li Y, Ramsey JT, Garcia M, Mathura E, Arao $Y$ (2019) Physiological and pathological roles of estrogen receptor. In: Zhang $X$ (ed) Estrogen receptor and breast cancer. Springer, New York, pp 15-47. https://doi.org/10.1007/978-3-319-99350-8_2

Lakhani NJ, Venitz J, Figg WD, Sparreboom A (2003) Pharmacogenetics of estrogen metabolism and transport in relation to cancer. Curr Drug Metab 4(6):505-513. https://doi.org/10.2174/1389200033489244

Ley RE, Peterson DA, Gordon JI (2006) Ecological and evolutionary forces shaping microbial diversity in the human intestine. Cell 124(4):837-848. https ://doi.org/10.1016/j.cell.2006.02.017

Maanen JV, Moonen E, Maas LM, Kleinjans J, Schooten FV (1994) Formation of aromatic DNA adducts in white blood cells in relation to urinary excretion of 1-hydroxypyrene during consumption of grilled meat. Carcinogenesis 15(10):2263-2268. https://doi.org/10.1093/carcin/15.10.2263

Pinyakong $\mathrm{O}$, Habe $\mathrm{H}$, Omori $\mathrm{T}$ (2003) The unique aromatic catabolic genes in sphingomonads degrading polycyclic aromatic hydrocarbons (PAHs). J Gen Appl Microbiol 49(1):1-19. https://doi.org/10.2323/jgam.49.1

Platet N, Cathiard AM, Gleizes M, Garcia M (2004) Estrogens and their receptors in breast cancer progression: a dual role in cancer proliferation and invasion. Crit Rev Oncol Hematol 51(1):55-67. https://doi.org/10.1016/j.critr evonc.2004.02.001

Plottel CS, Blaser MJ (2011) Microbiome and malignancy. Cell Host Microbe 10(4):324-335. https://doi.org/10.1016/j.chom.2011.10.003

Richie RC, Swanson JO (2003) Breast cancer: a review of the literature. J Insur Med 35(2):85-101

Shapira I, Sultan K, Lee A, Taioli E (2013) Evolving concepts: how diet and the intestinal microbiome act as modulators of breast malignancy. Int Sch Res Not 2013:1-10. https://doi.org/10.1155/2013/693920

Thomas MP, Potter BV (2013) The structural biology of oestrogen metabolism. J Steroid Biochem Mol Biol 137:27-49. https://doi.org/10.1016/j.jsbmb .2012.12.014

Urbaniak C, Burton JP, Reid G (2012) Breast, milk and microbes: a complex relationship that does not end with lactation. Women's Health 8(4):385-398. https://doi.org/10.2217/WHE.12.23

Urbaniak C, Gloor GB, Brackstone M, Scott L, Tangney M, Reid G (2016) The microbiota of breast tissue and its association with breast cancer. Appl Environ Microbiol 82(16):5039-5048. https://doi.org/10.1128/AEM.01235 $-16$

White AJ, Bradshaw PT, Herring AH, Teitelbaum SL, Beyea J, Stellman SD, Steck SE, Mordukhovich I, Eng SM, Engel LS (2016) Exposure to multiple sources of polycyclic aromatic hydrocarbons and breast cancer incidence. Environ Int 89:185-192. https://doi.org/10.1016/j.envint.2016.02.009

Xuan C, Shamonki JM, Chung A, DiNome ML, Chung M, Sieling PA, Lee DJ (2014) Microbial dysbiosis is associated with human breast cancer. PLoS ONE 9(1):e83744. https://doi.org/10.1371/journal.pone.0083744

Zhang XH, Giuliano M, Trivedi MV, Schiff R, Osborne CK (2013) Metastasis dormancy in estrogen receptor-positive breast cancer. Clin Cancer Res 19(23):6389-6397. https://doi.org/10.1158/1078-0432.CCR-13-0838

\section{Publisher's Note}

Springer Nature remains neutral with regard to jurisdictional claims in published maps and institutional affiliations. 